\title{
Detection of small GTP binding proteins showing GTPase and GTPIATP binding activities in the ovary of the american cockroach, Periplaneta americana, during oogenesis
}

\author{
Mohamed Elmogy ${ }^{1,2, *}$, Azza M. Elgendy ${ }^{1}$, Makio Takeda ${ }^{3}$ \\ ${ }^{1}$ Department of Entomology, Faculty of Science, Biotechnology program, Cairo University, Giza, Egypt \\ ${ }^{2}$ Department of Biology, Faculty of Applied Science, Umm Al-Qura University, Makkah, Saudi Arabia \\ ${ }^{3}$ Insect Science Laboratory, Graduate School of Agricultural, Kobe University, Kobe, Japan
}

\section{Email address:}

elmoogy@yahoo.com (M. Elmogy)

\section{To cite this article:}

Mohamed Elmogy, Azza M. Elgendy, Makio Takeda. Detection of Small GTP Binding Proteins Showing GTPase and GTP/ATP Binding Activities in the Ovary of the American Cockroach, Periplaneta Americana, during Oogenesis. American Journal of BioScience. Vol. 2, No. 3, 2014, pp. 106-110. doi: 10.11648/j.ajbio.20140203.15

\begin{abstract}
In the present study, the small GTP binding proteins involved in the regulatory mechanism of vitellogenin $(\mathrm{Vg})$ endocytotic vesicles trafficking were detected, for the first time, in ovaries of the most basal hemimetabolus insect, Periplaneta americana during oogenesis. The ovarian GTPase activities were peaked during previtellogenic and early vitellogenic periods. Such activity coincides with vitellogenin receptors $(V g R s)$ and clathrin early expression during these developmental periods, suggesting the importance of GTPases not only in the process of vesicle formation and fusion but also in the process of early fluid phase endocytosis. Two small peaks of activities were monitored during the late vitellogenic period (days 8 and 10), suggesting a possible role of GTPases in $V g R s$ and clathrin recycling process. The [ $\left.\alpha^{32} \mathrm{P}\right]$-GTP binding assay analysis in different tissues revealed the presence of small GTP binding proteins of molecular weights 25,23 and 21 $\mathrm{kDa}$ in ovaries and head. However, a single binding signal band of 21 and $25 \mathrm{kDa}$ was each detected in the fat bodies and muscles, respectively. No binding was detected in the midgut and Malpighian tubules. However, the $23 \mathrm{kDa}$ protein detected was suggested as a probable cytosolic form of the $25 \mathrm{kDa}$ protein. The competition assay results indicated that the small ovarian GTP binding proteins could also bind ATP, suggesting that like GTP, ATP is a regulatory nucleotide for the ovarian small proteins detected during oogenesis. The present study will pave the way for more understanding of the mechanisms that regulate $V g$ transport machinery in hemimetabolous insects.
\end{abstract}

Keywords: GTP/ATP Binding, GTPase, Vitellogenesis, Endocytosis, American Cockroach

\section{Introduction}

Developing oocytes of all oviparous species, including insects, accumulate massive amounts of yolk to ensure ample supply of nucleic acids, proteins, lipids, phosphate, carbohydrates, ion and vitamins necessary for independent development of the future embryos. Although several types of yolk protein precursors are accumulated by insect oocytes, vitellogenin $V g$ is the most abundant in all insect species [1]. $\mathrm{Vg}$ is taken up by competent oocytes through channels between follicular cells which resulted from their shrinkage [2]. The follicle cells shrinkage results from a $\mathrm{Na}^{+} / \mathrm{K}^{+}$-ATPase activation [3]. The $V g s$ accumulated and transported into the growing oocytes by membrane bound receptors $(V g R s)$ through receptor-mediated endocytosis. [4, 5]. $\mathrm{Vg} / \mathrm{VgR}$ complexes concentrate in clathrin coated pits that invaginate and pinch off to form intracellular coated vesicles or early endosomes. Endosomes first form clusters and their aggregation required ATP [6]. The processes of vesicle budding, docking, and fusion are regulated by a series of generic and compartment-specific proteins [7]. Endosomal biogenesis, fusion and maturation are controlled by small GTPases of Rab family [8]. The oocyte requires protein machinery to accomplish each of these processes at every stage of vesicle intracellular trafficking [9].

Small GTP- binding proteins are known to regulate a wide variety of cell functions in eukaryotes, from yeast to human, including: cell proliferation, cytoskeleton 
organization, and intracellular trafficking [10]. Rab proteins comprise the largest subgroup of the Ras superfamily of small GTPases, which specifically act as regulators of intracellular trafficking between subcellular compartments of eukaryotic cells [11]. According to the structures of the small GTP-binding proteins, they have two inter-convertible forms: guanosine diphosphate (GDP) bound inactive form and guanosine triphosphate (GTP) bound active form. The GTP bound form is converted by the action of the intrinsic GTPase activity to the GDP bound form. On the subcellular membrane, the GTP bound form binds many effector proteins and performs a variety of cellular processes then, they return to cytosol as the inactive GDP-bound form [12, 13, 14].

Adenosine triphosphate (ATP) is a signal molecule of protein phosphorylation of protein kinases and is also necessary as energy material for membrane transporters [15].

The yolk protein uptake by developing oocytes has been the subject of intensive research, especially in holometabolous species, like mosquitoes and Drosophila melanogaster [1, 16]. However, studies based on less modified hemimetabolous species, like cockroaches which have panoistic type ovaries (no nurse cells associated with oocytes), are scarcer.

In an attempt to characterize all the structural elements of the american cockroach, P.americana Vgs transport machinery, two major components of the coated vesicles, the ligand-vitellogenin $(V g)$ and its receptor $(V g R)$, were previously cloned and characterized at both biochemical and molecular levels including developmental expression, localization and sequencing analysis $[17,18,19,20,21,22]$ Recently, we reported a possible role for $P$. americana clathrin heavy chain (Pam CHC), the main component of the coated vesicles, in the early fluid phase endocytosis (pinocytosis) in addition to its role in the receptor mediated endocytosis [23].

The present study aims to investigate the small GTP-binding proteins, the most basal insect ovarian proteins yet examined, involved in vesicles intracellular trafficking in the ovary of the hemimetabolous cockroach, $P$. americana (Dictyoptera, Blattidae), during oogenesis. The GTPase activity was measured in ovaries during oogenesis. The molecular weights and the numbers of the small GTP-binding proteins involved during oogenesis were detected, by using GTP binding assay, in different tissues and in the ovaries during different developmental periods. The detected small GTP binding proteins have shown ATP binding activities in the ovaries during oogenesis.

\section{Materials and Methods}

\subsection{Insect Rearing and Sample Collection}

Cultures of $P$. americana were maintained in the laboratory, fed with artificial diet (MF, Oriental Yeast Crop.) and water, at $26^{\circ} \mathrm{C}$, in the plastic containers of about $50 \mathrm{X}$ 100 X $30 \mathrm{~cm}$. Newly emerged females were collected from stock colonies and kept separately under constant darkness conditions at $26^{\circ} \mathrm{C}$, until required. Female ovaries (at different developmental periods), fat bodies, Malpighian tubules, midgut and muscles, were isolated in phosphate buffered saline (1x PBS: $2 \mathrm{mM} \mathrm{KH}_{2} \mathrm{PO}_{4}, 137 \mathrm{mM} \mathrm{NaCl}$, $10 \mathrm{mM} \mathrm{Na} \mathrm{NPO}_{4}, 2.7 \mathrm{mM} \mathrm{KCl}, \mathrm{PH} 7.4$ ), and used immediately for post nuclear supernatant preparations. Different tissues at different developmental periods are homogenized in $(250 \mathrm{mM}$ Sucrose, $20 \mathrm{mM}$ HEPES, 0.5 mM EGTA, $\mathrm{pH}$ 7.0), supplemented with protease inhibitor cocktail (Complete, Roche Diagnosis GmbH, Mannheim, Germany). The homogenates were centrifuged at $800 \mathrm{xg}$ for $10 \mathrm{~min}$ to generate post-nuclear supernatants (PNS), as described in [6]. PNS for ovaries were used fresh for GTPase activity experiment.

\subsection{Measurement of Gtpase Activity}

The QuantichromTMATPase/GTPase assay kit (BioAssay Systems, CA, USA) was used for determining GTPase activities in a microplate format. Briefly, Post nuclear supernatants (PNSs) of ovaries at different developmental periods $(10 \mathrm{mg} / \mathrm{ml})$ were mixed with $20 \mu \mathrm{l}$ of assay buffer ( $40 \mathrm{mM}$ Tris-HCl, $80 \mathrm{mM} \mathrm{NaCl}, 8 \mathrm{mM} \mathrm{MgCl}_{2}$, $1 \mathrm{mM}$ dithiothreitol, $1 \mathrm{mM}$ EDTA, $\mathrm{pH} 7.5)$, and incubated at $37^{\circ} \mathrm{C}$ for $30 \mathrm{~min}$ in presence or absence of $10 \mu \mathrm{l}(4 \mathrm{mM})$ GTP. The reaction was terminated by adding $200 \mu \mathrm{l}$ of malachite green reagent (provided with the kit), and incubation for $30 \mathrm{~min}$ at room temperature. After incubation, this reagent forms a stable dark green color with liberated phosphate, which is measured on a plate reader at a wavelength of $620 \mathrm{~nm}$. The standard phosphate curve was prepared and measured according to the instruction of the supplier. In control experiments, the above reaction was carried out without PNS. The amount of inorganic phosphate liberated was calculated by subtracting the values for control from those obtained for PNSs.

\subsection{Determination of the Small GTP Binding Proteins}

GTP binding assay on membranes was performed by the method in [24] for qualitative determination of GTP binding protein activity. Briefly, equal amounts of protein extracts $(10 \mu \mathrm{g})$ were separated on $12 \%$ SDS-polyacrylamide gels, and transferred to $0.45 \mu \mathrm{m}$ Immobilon-P membranes. The membranes were pre-incubated overnight at $4{ }^{\circ} \mathrm{C}$ in the binding buffer $[50 \mathrm{mM}$ Tris- $\mathrm{HCl}(\mathrm{pH} 7.4)$, containing $5 \mathrm{mM}$ $\mathrm{MgCl}_{2}, 0.3 \%$ Tween $20,0.5 \mathrm{mM}$ EDTA, and 0.25 non-fat milk], followed by incubation with $1 \mathrm{nM}\left[\alpha^{32} \mathrm{P}\right]$-GTP $(1000$ $\mathrm{Ci} / \mathrm{mmol}$ ) (MP Biomedical, Ohaio, USA) in the binding buffer. After washing three times with the binding buffer without non-fat milk, the GTP binding proteins were detected by exposing the blots to x-ray film for $16 \mathrm{~h}$. 


\subsection{Competition for [ $\alpha^{32}$ P]-Radiolabeled GTP Binding to PNS by Nucleotides}

For specificity and competition of binding, the above $\left[\alpha^{32} \mathrm{P}\right]$-labeled GTP binding assay was carried out in the presence of $1 \mathrm{mM}$ of individual non-radiolabeled nucleotides [Adenosine 5'-triphosphate (ATP), and Guanosine 5'-triphosphate (GTP)] (Wako chemicals Ind., Osaka, Japan). The displacement activity was qualitatively referred to the intensity of each GTP binding protein band detected.

\subsection{Data Analysis}

Experimental data were analyzed using Origin software (OriginLab, Northampton, MA, USA).

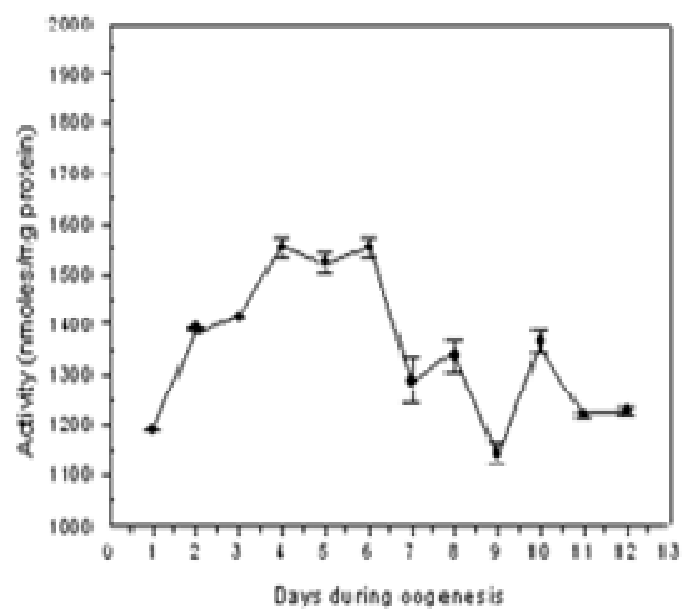

Figure 1. GTP hydrolysis by GTPases of the female P. americana ovaries during oogenesis. GTPases activities were assayed in post nuclear supernatants prepared from ovaries during oogenesis from dayl to day 12, as described in materials and methods. The amounts of liberated phosphates were calculated after subtraction of control value and GTPase activity expressed as nmoles of liberated phosphates/ mg protein. Each datum point is a mean $\pm S D(n=3)$.

\section{Results and Discussion}

\subsection{GTP Hydrolysis by GTPases during Oogenesis}

The GTPase activities in the PNSs preparations of $P$. americana ovaries during days from adult female post emergence (the first vitellogenic cycle: day 1 to day 12) were shown in Figure.1. The GTP hydrolysis reactions proceeded linearly during the previtellogenic period from day one of adult female emergence and reached its maximum activity at day 4. Similarly, P. americana $V g R$ and clathrin heavy chain $(\mathrm{CHC})$ proteins were also observed early in the ovary from the day of adult female emergence. However, Vg uptake occurred on day 5, one day after $V g$ first appear in the haemolymph $[20,22]$. Early, light and ultrastructural studies of vitellogenesis and oogenesis on P. americana ovaries demonstrated specialization of the oolemma, in the form of microvilli in oocytes and caveolae formation during the previtellogenic period [24]. Such a high GTPase activity was continued during the days of the early vitellogenic periods until day 6 . Accordingly, the obtained GTPase activity during previtellogenic and early vitellogenic period together with $V g R$ and $C H C$ developmental profiles during the same period, may suggest the importance of the small GTP binding proteins not only in the process of vesicle budding, docking, and fusion but also in the process of fluid phase endocytosis. A sudden drop in the measured activity was monitored at day 7 which was followed by two small peaks of activities during the late vitellogenic periods on days 8 and 10, suggesting a possible role of small GTP binding proteins in the recycling of $\mathrm{VgRS}$ [20] and clathrin [22].

\subsection{Binding of $\left[a^{32} P\right]-G T P$ to Postnuclear Supernatants of Different Tissues}

In order to detect the small GTP binding proteins in different tissues of $P$. americana during oogenesis, postnuclear supernatants from ovaries, head, fat bodies, muscles, midgut, and Malpighian tubules were electrophoretically separated, blotted, and the blotted proteins were incubated with $\left[\alpha^{32} \mathrm{P}\right]-\mathrm{GTP}$. The radioactive signal bands detected (Fig.2) reveal the proteins bound to $\left[\alpha^{32} \mathrm{P}\right]$-GTP. As shown in figure $2 \mathrm{~A}$, the $\left[\alpha^{32} \mathrm{P}\right]$-GTP bound proteins of molecular weights 25,23 and $21 \mathrm{kDa}$ were detected in ovaries and head. Similarly, several GTPases are detected in mammalian central nervous system and found to regulate different steps of endocytic process at the level of post synapsis [7]. However, in the fat bodies and Muscles a single binding signal of $21 \mathrm{kDa}$ and $25 \mathrm{kDa}$ were detected, respectively. No binding signals could be detected in midgut and Malpighian tubules. Depending on the bands signal intensities obtained, most of GTP binding activities were exclusively occurred in the ovarian tissues during oogenesis.

\subsection{Developmental Pattern of $\left[\alpha^{32} P\right]-G T P$ Binding to the Ovarian Tissues}

In order to determine the developmental profile of $P$. americana ovarian small GTP binding proteins, $\left[\alpha^{32} \mathrm{P}\right]-\mathrm{GTP}$ binding assay was performed with PNSs prepared from ovaries during different periods of oogenesis. The assay results indicated different levels of binding signal intensities and kinetics for each small GTP binding protein (Fig. 2B). The $25 \mathrm{kDa}$ binding signal was most abundant during the previtellogenic period, suggesting a probable role in the vesicle formation. However, the $21 \mathrm{kDa}$ binding signal was most abundant during late vitellogenic period, suggesting a probable role in the recycling fate of the vitellogenin receptors. Interestingly, all small GTP binding proteins detected have shown high binding signals during days 4, 6, 8, 10 with different intensities, suggesting that they may interplay role in vitelogenin endocytosis process during these periods. The molecular weights and the developmental profile obtained for P. americana ovarian small GTP proteins, indicate that they might belong to Rabs subfamily. However, further investigations will be needed to determine the identity and full molecular characterization for each protein detected in the present work. The developmental 
profile results obtained from the $\left[\alpha^{32} \mathrm{P}\right]-\mathrm{GTP}$ binding assay (Fig. 2B), are consistent with those obtained from the GTPase activity measurement assay (Fig. 1).

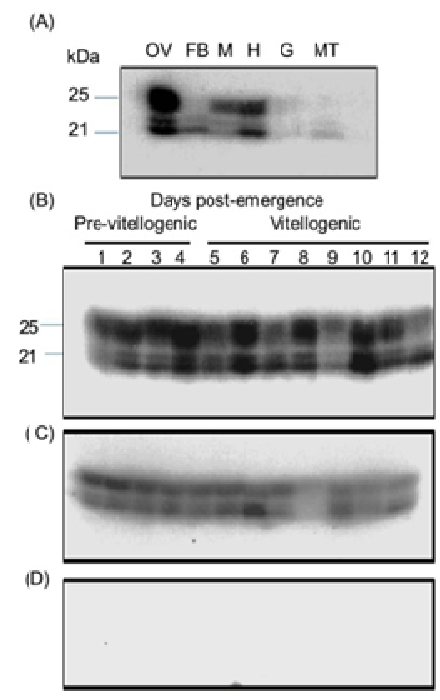

Figure 2. Detection of P. americana small GTP binding proteins during oogenesis (A) Tissue specific pattern. Equal amounts (10 $\mu \mathrm{g})$ of postnuclear supernatants (PNSs) isolated from ovaries (OV), Fat bodies (FB), Muscles $(M)$, Head (H), Midgut (G), and Malpighian tubules (MT) were electrophoresed on $12 \%$ SDS-PAGE, blotted on to Immobilon-P membranes, incubated with [ $\left.\alpha^{32} P\right]-G T P$ in binding assay buffer, and washed blots exposed to $x$-ray for imaging. (B) Developmental pattern. Equal amounts $(10 \mu \mathrm{g})$ of PNSS isolated from ovaries at the indicated developmental periods and blots were assay as in A. Competition assay: similar blots for the ovarian PNSs during the indicated developmental periods were assayed with $\left[\alpha^{32} P\right]-G T P$ in presence of non-radiolabeled competitors (c) ATP and (D) GTP.

Recently, we have cloned the cDNA encoding $P$. americana small GTP binding Rab5 from ovaries (GenBank accession number AB470337) and immunolocalized its 25 $\mathrm{kDa}$ protein to oocyte cortex (Elmogy et al., unpublished data). The Rab5 of small GTP binding proteins are known to be synthesized in the cytosol, but as a result of their modification with two copies of isoprenoid gerany-geranyl, they become attached to the cytosolic face of membranes [25]. Therefore, the $23 \mathrm{kDa}$ protein detected (Fig. 2B) was suggested as a probable cytosolic form of the $25 \mathrm{kDa}$ protein, however, further confirmation will be needed.

In insects, Rab(s) of small GTP binding proteins have been the subject of many studies, especially in holometabolous species, like Drosophila melanogaster, in which Rab11 was found to regulate eye development and generate cell polarity during oogenesis [26, 27]; Rab11 and Rab6 were found to play important roles in processing and transport of rhodopsins [28, 29]; Rab5 was found to be involved in trafficking at synapses [30]. While in the brain of Bombyx mori, Rab14 and RabN1, N2 were biochemically characterized $[31,32,13]$.

\subsection{Competitive Inhibition of $\left[\alpha^{32} P\right]-G T P$ Binding with ATP and GTP}

Next, the competitive inhibition of $\left[\alpha^{32} \mathrm{P}\right]-$ GTP binding to $P$. americana ovarian small GTP binding proteins with non-radiolabled (cold) ATP and GTP was examined. In figure $2 \mathrm{C}$, the addition of ATP could partially inhibit $\left[\alpha^{32} \mathrm{P}\right]-\mathrm{GTP}$ binding. However, the addition of GTP could completely inhibit $\left[\alpha^{32} \mathrm{P}\right]-\mathrm{GTP}$ binding (Fig. 2D). The obtained results from the competition assay indicated that the small ovarian GTP binding proteins could also bind ATP and consequently might show ATPase activity. Accordingly, like GTP, ATP is a regulatory nucleotide for the $P$. americana ovarian proteins, detected in the present study, during oogenesis. Similarly, ATP was defined as energy material for many of the pumps such as ion transporters and molecular motors like myosin in addition to protein transport related to Rab proteins such as Rab14 in Bombyx mori brain [13].

\section{Conclusion}

The present study give the small GTP/ATP binding proteins (25 and $21 \mathrm{kDa}$ ) detected, for the first time, in the ovaries of $P$. americana during oogenesis, an exciting integrative function between cell metabolic status and membrane trafficking. This work will pave the way for the identification and molecular characterization of the generic and critical compartment specific proteins, the potential targets for pest control, that regulate the mechanism of $V g$ transport machinery in the american cockroach, $P$. americana .

\section{References}

[1] E.S., Snigirevskaya, and A.S., Raikhel, "Receptor mediated endocytosis of yolk proteins in insect oocytes. In: Raikhel A. S., Sappington T. W. (Eds.), Progress in vitellogenesis. Reproductive Biology of Invertebrates, vol. XII. Part B. Science Publishers, Inc., Enfield, USA-Plymouth UK,2005, pp. 199-228.

[2] A.S., Raikhel, and T.S. Dhadialla, "Accumulation of yolk proteins in insect oocytes. Ann. Rev. Entomol., vol. 73 pp. 217-251, 1992.

[3] K. G. Davey, "Hormonal integration of egg production in Rhodnius prolixus," American Zoologist, vol.33, pp.397-402. 1993.

[4] M., Tufail, M., Takeda, "Molecular characteristics of insect vitellogenins. J. Insect Physiol, vol. 54, pp.1447-1458, 2008.

[5] M., Tufail, and M., Takeda, "Insect vitellogenin/lipophorin receptors: Molecular structures, role in oogenesis, and regulatory mechanisms. J. Insect Physiol., vol. 55, pp. 88-104, 2009.

[6] R. Diaz, L.S. Mayorga, L.E. Mayorga, and P. Stahl, "In vitro clustering and multiple fusion among macrophage endosomes," Journal of Biological Chemistry, vol.264, no.22, 13171-13180, 1989.

[7] P. D`Adamo, M. Masetti, V. Bianchi, L. More', M. Mignogna, and S. Gatti, "RAB GTPases and RAB-interacting proteins and their role in the control of cognitive functions", Journal of neurobiology review, Doi.org/10.1016/J.neubiorev.2013.12.009, 2014. 
110 Mohamed Elmogy et al:: Detection of Small GTP Binding Proteins Showing GTPase and GTP/ATP Binding Activities in the Ovary of the American Cockroach, Periplaneta Americana, during Oogenesis

[8] M., Zerial, and H., McBride H., "Rab proteins as membrane organizers. Nat. Rev. Mol. Cell Biol., vol. 2, pp. 107-117, 2001.

[9] J. Armstrong, "How do Rab proteins function in membrane traffic?" International Journal of Biochemistry and Cell Biology, vol.32, pp. 303-307, 2000.

[10] Y., Takai, T., Sasaki, and T., Matozaki, "Small GTP-binding proteins. Physiol. Rev., vol. 81, no.1, pp. 153-208, 2001.

[11] I. Jordens, M. Marsman, C. Kuijl, and J. Neefjes, "Rab proteins connecting transport and vesicle fusion," Traffic, vol.6, pp. 1070-1077, 2005.

[12] M.T. Handley, and R.D. Burgoyne, "The Rab27 effector Rabphilin, unlike Granuphilin and Noc2, rapidly exchanges between secretory granules and cytosol in PC12 cells," Biochemical Biophysical Research Communication, vol.373, pp. 275-281, 2008 .

[13] T., Uno, T., Moriwaki, Y., Isoyama, Y., Uno, K., Kanamaru, H., Yamagata, M., Nakamura and M., Takagi, "Rab14 from Bombyx mori (Lepidoptera: Bombycidae) shows ARPase activity. Biol. Lett. (doi: 10.1098/rsbl.2009.0878), 2010.

[14] J. Blumer, Y. W. Wu, R. S. Goody, and A. Itzen, "Specific localization of Rabs at intracellular membranes", Biochemical Society Transactions, Vol.40, no. 6, pp.14211425,2012

[15] P., Liu, R., Bartz, J.K., Zehmer, Y.S., Ying, M., Zhu, G.M., Serrero, and R/G., Anderson. Rab-regulated interaction of early endosomes with lipid droplets. Biochem. Biophys. Acta., vol. 1773, pp. 784-793, 2007.

[16] R., Van Antwerpen, D.Q.D., Pham, and R., Ziegler, Accumulation of lipids in insect oocytes. In Progress in Vitellogenesis (Raikhel A.S., Sappington, T.W. eds); Reproductive Biology of Invertebrates (Adiyodi, K.G., Adiyodi R.G., Series Editors), Science Publishers, Inc., Enfield, NH; Plymouth UK, Vol XII. Part B, 2005, pp. 265-288.

[17] M., Tufail, J. M., Lee, M., Hatakeyama, K., Oishi, and M., Takeda, Cloning of vitellogenin cDNA of the american cockroach, Periplaneta americana (Dictyoptera), and its structural and expression analyses. Arch. Insect Biochem. Physiol., vol. 45, pp. 37-46, 2000.

[18] M., Tufail, M., Hatakeyama, and M. Takeda. Molecular evidence for two vitellogenin genes and processing of vitellogenins in the american cockroach, Periplaneta americana. Arch. Insect Biochem. Physiol., vol. 48, pp. 72-80, 2001.

[19] M., Tufail, A.S., Raikhel, M. Takeda. Biosynthesis and processing of insect vitellogenins. In Progress in Vitellogenesis (Raikhel A.S. and Sappington T.W. eds); Reproductive Biology of Invertebrates (Adiyodi K.G. and Adiyodi R.G., Series Editors), Science Publishers, Inc., Enfield, NH; Plymouth, UK., Vol XII. Part B, 2004, pp. 1-32.

[20] M., Tufail, and M., Takeda M. Molecular cloning, characterization and regulation of the cockroach vitellogenin receptor during oogenesis. Insect Mol. Biol., vol. 14, pp. 389-401, 2005.

[21] M., Tufail, and M., Takeda. Molecular characteristics of insect vitellogenins. J. Insect Physiol., vol. 54, pp. 1447-1458, 2008.

[22] A. M. Elgendy, M. Elmogy, M. Tufail, and M. Takeda, "Developmental expression profile of cockroach vitellogenin genes Vg1 and2," Animal Biology Journal, vol.1, pp. 39-48, 2009.

[23] M. Elmogy, A.M. Elgendy, W.M. Alamodi, and M. Takeda, "Molecular characterization, developmental expression and immunolocalization of clathrin heavy chain in the ovary of the american cockroach, Periplaneta americana during oogenesis," Journal of Advanced laboratory Research in Biology, vol.3, no.4, pp. 313-318, 2012.

[24] Y., Shirai, N., Sakai, and N., Saito. 1998. Subspecies-specific targeting mechanism of protein kinase C. Jpn. J. Pharmacol., vol. 78, no. 4, pp. 411-418, 1998.

[25] E. Anderson, "Oocyte differentiation and vitellogenesis in the roach Periplaneta americana," Journal of Cell Biology, vol.20, pp.131-153, 1964.

[26] A. Itzen, and R.S. Goody, "GTPases involved in vesicular trafficking: structures and mechanisms," Seminar of Cell and Developmantal Biology, vol.22, no.1, pp. 48-56, 2011.

[27] G. Dollar, E. Struckhoff, J. Michaud, and R.S. Cohen, "Rab11 polarization of the Drosophila oocyte: a novel link between membrane trafficking, microtubule organization, and oskar mRNA localization and translation," Development, vol.129, pp. 517-526, 2002.

[28] X.B., Li, A.K., Satoh, and D.F., Ready. Myosin V, Rab11, and dRip11 direct apical secretion and cellular morphogenesis in developing Drosophila photoreceptors. J. Cell. Biol., vol.177, pp. 659-669, 2007.

[29] A.K. Satoh, F., Tokunaga, S., Kawamura, and K., Ozaki. In situ inhibition vesicle transport protein processing in the dominant negative Rab1 mutant of Drosophila. J. Cell Sci., vol. 110, pp. 2943-2953, 1997.

[30] K. M., Shetty, P., Kurada, and J.E., Otousa. Rab6 regulation rhodopsin transport in Drosophila. J. Biol. Chem., vol. 273, pp. 20425-20430, 1998.

[31] T., Wucherpfennig, M., Wilsch-Brauninger, and M., Gonzalez-Gaitan. Role of Drosophila Rab5 during endosomal trafficking at the synapse and evoked neurotransmitter release. J. Cell Biol., vol. 161, pp. 609-624, 2003.

[32] T. Uno, A. Nakao, and C. Katsurauma. Phosphorylation of Rab proteins from the brain of Bombyx mori. Arch. Insect Biochem. Physiol., vol. 57, pp. 68-77, 2004.

[33] T., Uno, T. Moriwaki, M. Nakamura, M. Matsubara, H. Yamagata, K., Kanamaru, and M. Takagi. Biochemical characterization of Rab proteins from Bombyx mori. Arch. Insect Biochem. Physiol. 2008 (doi: 10.1002/arch.20273). 